\title{
Prediction of the risk of mortality using risk score in patients with coronary heart disease
}

\author{
Qian Chen ${ }^{1,2}$, Ding Ding ${ }^{1}$, Yuan Zhang ${ }^{3}$, Yunou Yang ${ }^{1}$, Qing Li $^{1}$, Xuechen Chen ${ }^{1}$, \\ Gang $\mathrm{Hu}^{2}$, Wenhua Ling ${ }^{1}$ \\ ${ }^{1}$ Guangdong Provincial Key Laboratory of Food, Nutrition and Health, Department of Nutrition, School of Public Health, Sun \\ Yat-sen University, Guangdong, China \\ ${ }^{2}$ Chronic Disease Epidemiology Laboratory, Pennington Biomedical Research Center, Baton Rouge, Louisiana, USA \\ ${ }^{3}$ Department of Cardiology, General Hospital of Guangzhou Military Command of People's Liberation Army, Guangdong, China \\ Correspondence to: Wenhua Ling, email: lingwh@mail.edu.cn \\ Gang Hu, email: gang.hu@pbrc.edu
}

Keywords: coronary heart disease, risk score, mortality, cohort study

Received: August 23, $2016 \quad$ Accepted: October 17, 2016

Published: November 07, 2016

\section{ABSTRACT}

Background: The aim of the study is to develop risk scores with traditional factors for all-cause and cardiovascular mortality among coronary heart disease (CHD) patients.

Methods and Results: We performed a prospective cohort study of 1911 CHD patients aged 40 and older. Cox models were used to estimate the association of traditional factors [sex, age, fasting blood glucose (FBG), high-density lipoprotein cholesterol (HDL-C), low-density lipoprotein cholesterol (LDL-C), blood pressure (BP), and cigarette use] and risk scores with all-cause and cardiovascular mortality. During a mean follow-up of 4.9 years, 232 deaths were identified, 159 of which were cardiovascular-related. Both 4-year and whole follow-up data showed age, sex, HDL-C, LDL-C, and FBG were significantly associated with the risk of mortality, while $B P$ and smoking were not significant predictors in all models. We incorporated age, sex, FBG, HDL-C, and LDL-C to establish risk scores for all-cause and cardiovascular mortality in the 4-year and whole follow-up study. These risk scores were positively associated with the risk of death as quartiles and continuous variables. Assessed by the area under the receiver operating characteristic curves (AUROCs), these risk scores demonstrated strong discriminatory capacity, from 0.744 to 0.763 ; and the utility of these scores was confirmed with AUROCs from 0.736 to 0.756 (all $P<0.001$ ) in a validation cohort of 1506 CHD patients with a mean follow-up of 4.7 years.

Conclusions: These simple risk score assessments, including a set of traditional risk factors, might improve the identification of high-risk CHD patients for a more intensive secondary prevention treatment.

\section{INTRODUCTION}

Cardiovascular disease (CVD) is the leading cause of deaths worldwide with more than half from coronary heart disease (CHD) [1]. Although the mortality from heart disease has declined in recent years in the developed countries, the burden of CHD still remains alarmingly high, especially in the developing countries [1-3]. Various risk score systems have been developed to estimate the risk of cardiovascular events (including mortality) within a given time frame among the general population [4-7]. The most common score is from the Framingham Study [5] including age, categories of blood pressure (BP), cigarette use, total cholesterol or low-density lipoprotein cholesterol (LDL-C), highdensity lipoprotein cholesterol (HDL-C), and diabetes. Although age, gender, hyperglycemia, dyslipidemia, hypertension and cigarette use are still important for CHD prognosis, convenient and efficient scoring assessments composed of these traditional factors for quantifying the long-term mortality risk among patients with CHD are limited. 
Currently, few studies have developed scores or predictions for cardiovascular outcomes among CHD patients [8-10]. Most of these score assessments were developed among acute coronary syndrome (ACS) patients for short-term outcomes prediction, and were all performed in the developed countries. In addition, these scoring systems included many biomarkers, such as angiographic results, electrocardiographic changes or indicators of liver and renal dysfunction, some of which might not be detected for every patient. Practically, a risk stratification tool with routine clinical measurements which would be available for every patient might be simple and easy to understand and calculate by physicians as well as patients. Furthermore, since secondary prevention of CHD is targeted on the risk-reduction clinical treatment and self-management, knowing risk status by patients themselves would have an important impact on supporting and broadening the merits of treatments. The aim of the present study was to develop a simple predictive risk score using traditional factors to estimate the long-term risk of all-cause and cardiovascular mortality among patients with CHD.

\section{RESULTS}

General characteristics of the study population of the Guangdong Coronary Artery Disease Cohort (GCADC) study (as derivation cohort) at baseline were shown in Table 1. We totally studied 1911 CHD patients in the GCADC study; the mean age was 63.6 years, and $65.1 \%$ were men. During the mean 4.9 years of followup, 232 deaths were identified, 159 of whom were due to cardiovascular causes. Compared with patients who survived during the follow-up, non-survivors were more likely to be older, had lower diastolic blood pressure (DBP) and higher fasting blood glucose (FBG), and had a high proportion of males, less education and less leisure-time physical activity. From the validation cohort of $1506 \mathrm{CHD}$ patients using electronic medical records from the same hospitals, 83 deaths were reported during the mean follow-up period of 4.7 years, 46 of them were cardiovascular-related.

The associations of different levels of selected risk factors at baseline with the risks of all-cause and cardiovascular mortality were shown in Table 2. After multivariate adjustment (alcohol consumption, marriage, family history of $\mathrm{CHD}$, types of $\mathrm{CHD}$, leisure-time physical activity, and BMI), gender, age, FBG, and HDL-C were significantly predictive for all-cause and cardiovascular mortality over 4-year and whole followup periods, whereas LDL-C was only predictive for cardiovascular mortality in the whole follow-up period. $\mathrm{BP}$ and smoking were not associated with an increased risk of mortality in either 4-year or whole period of follow-up. Systolic blood pressure (SBP) was positively correlated with LDL-C and HDL-C, and DBP was positively correlated with LDL-C and negatively correlated with FBG (all $\mathrm{r}<0.1, P<0.05$ ) (data no shown). Risk scores were given for different sexes, different levels of age, FBG, HDL-C and LDL-C (Table 3). BP and smoking have not been included in the final risk scores because they were not significant predictors in all multivariate models.

When we stratified risk scores into quartiles, the risk scores during both 4-year and the whole period of followup showed a graded increased association with the risks of all-cause and cardiovascular mortality (all $P>0.001$ ) (Table 4). Compared with patients in the lowest risk group (quartile 1 of risk score), the multivariable-adjusted hazard ratios (HRs) for all-cause and cardiovascular mortality among patients with the highest risk (quartile 4 of risk score) were 10.6 [95\% confidence interval (CI): 5.66-20.0] and 15.1 (95\% CI: 6.53-35.0) over 4-year follow-up; 8.86 (95\% CI: 5.15-15.3) and 14.5 (95\% CI: 6.68-31.6) over the whole follow-up, respectively. Each 1 value increase in risk score contributed to appropriately $10 \%$ increased risk of all-cause mortality (HR 1.10, 95\% CI: 1.08-1.13 for 4-year follow-up and HR 1.11, 95\% CI: 1.09-1.13 for whole period of follow-up) and cardiovascular mortality (HR 1.11, 95\% CI: 1.08-1.13 for 4-year follow-up and HR 1.10, 95\% CI: 1.08-1.12 for whole period of followup). The discrimination for risk scores was shown in Table 5. Assessed by the area under the receiver operating characteristic curve (AUROC), these four risk score models for risks of all-cause and cardiovascular mortality over 4-year and whole period of follow-up demonstrated the discriminatory capacity from 0.744 to 0.763 (all $P<0.001$ ) for the derivation cohort and 0.736 to 0.756 (all $P<0.001$ ) for the validation cohort, respectively.

\section{DISCUSSION}

We developed a simple risk score system (including sex, age, FBG, HDL-C, and LDL-C) for estimating prognosis of all-cause and CVD mortality among Chinese patients with CHD over a 4-year and a whole period of follow-up.

In the present study, we observed that men with CHD were at higher risk of mortality than women with CHD, which was the same as previous studies [4, 8]. As expected, age was always found to be the strongest predictor of the risk of mortality among patients with CHD. For other traditional factors studied, both impaired fasting glucose (FBG: 5.6-6.9 mmol/L) and diabetes were significantly associated with increased risks of mortality among CHD patients. We also found that the hazard ratios of mortality associated with FBG increased slightly with the increased length of follow-up, which indicated that FBG levels might have a significant long-term impact on CHD prognosis. The U-shape association of HDL-C with the risk of mortality was consistent with other studies $[11,12]$. Under particular conditions, HDL would lose its protective functions (antioxidant, anti-inflammation, 
Table 1: Baseline characteristics by mortality status among patients with coronary heart disease of the derivation cohort

\begin{tabular}{|c|c|c|c|c|}
\hline Characteristic & All patients & Survivors & Non-survivors & $P$ for difference \\
\hline $\mathrm{N}$ & 1911 & 1679 & 232 & \\
\hline Gender (male, \%) & 65.1 & 64.9 & 67.2 & 0.003 \\
\hline Age at baseline (yrs) & 63.6 & $62.5(0.26)$ & $71.7(0.71)$ & $<0.001$ \\
\hline Body mass index $\left(\mathrm{kg} / \mathrm{m}^{2}\right)$ & 23.9 & $23.9(0.08)$ & $23.6(0.22)$ & 0.26 \\
\hline Systolic blood pressure (mm Hg) & 134 & $134(0.56)$ & $132(1.54)$ & 0.17 \\
\hline Diastolic blood pressure (mm Hg) & 76.5 & $76.8(0.31)$ & $74.8(0.87)$ & 0.036 \\
\hline Fasting blood glucose $(\mathrm{mmol} / \mathrm{L})$ & 6.47 & $6.40(0.07)$ & $7.04(0.18)$ & 0.001 \\
\hline High-density lipoprotein cholesterol (mmol/L) & 41.9 & $1.09(0.01)$ & $1.05(0.02)$ & 0.08 \\
\hline Low-density lipoprotein cholesterol (mmol/L) & 115 & $2.96(0.02)$ & $3.03(0.07)$ & 0.30 \\
\hline Triglycerides (mmol/L) & 1.85 & $1.86(0.03)$ & $1.72(0.09)$ & 0.14 \\
\hline Total cholesterol (mmol/L) & 4.68 & $4.68(0.03)$ & $4.72(0.07)$ & 0.62 \\
\hline Married (\%) & 90.8 & 92.2 & 81.4 & 0.005 \\
\hline Years of education $(\%)$ & & & & 0.005 \\
\hline$\leq 9$ & 59.6 & 58.6 & 67.5 & \\
\hline $10-12$ & 22.1 & 21.9 & 23.3 & \\
\hline$\geq 13$ & 18.4 & 19.5 & 9.2 & \\
\hline Smoking (\%) & & & & 0.67 \\
\hline Never & 60.4 & 59.7 & 65.5 & \\
\hline Past & 8.8 & 8.5 & 11.6 & \\
\hline Current & 30.7 & 31.8 & 22.8 & \\
\hline Alcohol drinking (\%) & & & & 0.71 \\
\hline Never & 78.3 & 77.9 & 81.2 & \\
\hline Past & 6.7 & 6.7 & 6.6 & \\
\hline Current & 15.1 & 15.5 & 12.2 & \\
\hline Leisure-time physical activity (\%) & & & & $<0.001$ \\
\hline None & 33.5 & 31.9 & 50.0 & \\
\hline$\leq 30$ minutes/day & 21.6 & 21.3 & 24.6 & \\
\hline$>30$ minutes/day & 44.9 & 46.8 & 25.4 & \\
\hline Type of coronary heart disease $(\%)$ & & & & 0.60 \\
\hline Acute coronary syndrome & 59.8 & 59.8 & 59.5 & \\
\hline Chronic coronary heart disease & 40.2 & 40.2 & 40.5 & \\
\hline Family history of coronary heart disease $(\%)$ & 8.7 & 9.0 & 6.5 & 0.68 \\
\hline \multicolumn{5}{|l|}{ Use of medication before admission (\%) } \\
\hline Antihypertensive drugs & 48.9 & 47.9 & 55.7 & 0.88 \\
\hline Anti-diabetic drugs & 16.5 & 15.7 & 22.2 & 0.10 \\
\hline Lipid-lowering drugs & 12.1 & 12.3 & 10.9 & 0.60 \\
\hline Anti-platelet drugs & 19.7 & 18.8 & 25.7 & 0.13 \\
\hline
\end{tabular}

Abbreviations: Data are mean (standard error) or percentage; all variables are adjusted for age and gender, except for age (adjusted for gender only) and gender (adjusted for age only). 
Table 2: Hazard ratios for all-cause and cardiovascular mortality according to major risk factors among patients with coronary heart disease of the derivation cohort

\begin{tabular}{|c|c|c|c|c|c|c|c|c|c|}
\hline \multirow[b]{3}{*}{ Variable } & \multirow{3}{*}{$\begin{array}{c}\text { No. of } \\
\text { CHD } \\
\text { patients }\end{array}$} & \multicolumn{4}{|c|}{ 4-year follow-up } & \multicolumn{4}{|c|}{ Whole period of follow-up } \\
\hline & & \multicolumn{2}{|c|}{ No. of deaths } & \multicolumn{2}{|c|}{ Hazard ratios $(95 \% \mathrm{CI})^{a}$} & \multicolumn{2}{|c|}{ No. of deaths } & \multicolumn{2}{|c|}{ Hazard ratios $(95 \% \mathrm{CI})^{\mathrm{a}}$} \\
\hline & & Total & CVD & $\begin{array}{l}\text { All-cause } \\
\text { mortality }\end{array}$ & $\begin{array}{c}\text { CVD } \\
\text { mortality }\end{array}$ & Total & CVD & $\begin{array}{l}\text { All-cause } \\
\text { mortality }\end{array}$ & $\begin{array}{c}\text { CVD } \\
\text { mortality }\end{array}$ \\
\hline \multicolumn{10}{|l|}{ Gender } \\
\hline Female & 666 & 53 & 34 & 1.00 & 1.00 & 76 & 46 & 1.00 & 1.00 \\
\hline Male & 1245 & 127 & 95 & $\begin{array}{c}1.92(1.33- \\
2.77)\end{array}$ & $\begin{array}{c}2.32(1.49- \\
3.62)\end{array}$ & 156 & 113 & $\begin{array}{c}1.58(1.15- \\
2.17)\end{array}$ & $\begin{array}{c}1.95(1.31- \\
2.89)\end{array}$ \\
\hline \multicolumn{10}{|l|}{ Age, years } \\
\hline$<60$ & 682 & 18 & 12 & 1.00 & 1.00 & 25 & 16 & 1.00 & 1.00 \\
\hline $60-69$ & 569 & 41 & 35 & $\begin{array}{c}3.52(2.00- \\
6.18)\end{array}$ & $\begin{array}{c}4.74(2.43- \\
9.26)\end{array}$ & 56 & 44 & $\begin{array}{c}3.33(2.06- \\
5.39)\end{array}$ & $\begin{array}{c}4.33(2.41- \\
7.77)\end{array}$ \\
\hline$\geq 70$ & 660 & 121 & 82 & $\begin{array}{c}8.20(4.89- \\
13.7)\end{array}$ & $\begin{array}{c}8.48(4.50- \\
16.0)\end{array}$ & 151 & 99 & $\begin{array}{c}7.28(4.67- \\
11.3)\end{array}$ & $\begin{array}{c}7.63(4.38- \\
13.3)\end{array}$ \\
\hline$P$ for difference & & & & $<0.001$ & $<0.001$ & & & $<0.001$ & $<0.001$ \\
\hline \multicolumn{10}{|l|}{$\begin{array}{l}\text { Fasting blood } \\
\text { glucose, } \mathrm{mmol} / \mathrm{L}\end{array}$} \\
\hline$<5.6$ & 796 & 52 & 31 & 1.00 & 1.00 & 67 & 37 & 1.00 & 1.00 \\
\hline $5.6-6.9$ & 381 & 41 & 29 & $\begin{array}{c}1.55(1.02- \\
2.35)\end{array}$ & $\begin{array}{c}1.86(1.11- \\
3.11)\end{array}$ & 51 & 33 & $\begin{array}{c}1.64(1.13- \\
2.38)\end{array}$ & $\begin{array}{c}1.89(1.17- \\
3.04)\end{array}$ \\
\hline $\begin{array}{l}\geq 7.0 \text { or known } \\
\text { diabetes }\end{array}$ & 734 & 87 & 69 & $\begin{array}{c}1.75(1.23- \\
2.48)\end{array}$ & $\begin{array}{c}2.31(1.50- \\
3.57)\end{array}$ & 114 & 89 & $\begin{array}{c}1.87(1.37- \\
2.55)\end{array}$ & $\begin{array}{c}2.59(1.75- \\
3.84)\end{array}$ \\
\hline$P$ for difference & & & & 0.007 & 0.001 & & & $<0.001$ & $<0.001$ \\
\hline \multicolumn{10}{|l|}{$\begin{array}{l}\text { HDL cholesterol, } \\
\mathrm{mmol} / \mathrm{L}\end{array}$} \\
\hline$<1.03$ & 896 & 101 & 77 & $\begin{array}{c}1.63(1.17- \\
2.28)\end{array}$ & $\begin{array}{c}1.94(1.29- \\
2.92)\end{array}$ & 125 & 93 & $\begin{array}{c}1.53(1.15- \\
2.05)\end{array}$ & $\begin{array}{c}1.93(1.35- \\
2.78)\end{array}$ \\
\hline $1.03-1.54$ & 901 & 64 & 40 & 1.00 & 1.00 & 89 & 52 & 1.00 & 1.00 \\
\hline$\geq 1.55$ & 114 & 15 & 12 & $\begin{array}{c}2.11(1.18- \\
3.75)\end{array}$ & $\begin{array}{c}2.92(1.50- \\
5.68)\end{array}$ & 18 & 14 & $\begin{array}{c}1.67(0.99- \\
2.80)\end{array}$ & $\begin{array}{c}2.42(1.32- \\
4.44)\end{array}$ \\
\hline$P$ for difference & & & & 0.003 & 0.001 & & & 0.008 & $<0.001$ \\
\hline \multicolumn{10}{|l|}{$\begin{array}{l}\text { LDL cholesterol, } \\
\mathrm{mmol} / \mathrm{L}\end{array}$} \\
\hline$<2.59$ & 709 & 76 & 51 & 1.00 & 1.00 & 93 & 59 & 1.00 & 1.00 \\
\hline $2.59-4.14$ & 981 & 83 & 60 & $\begin{array}{c}0.95(0.69- \\
1.30)\end{array}$ & $\begin{array}{c}1.02(0.70- \\
1.50)\end{array}$ & 108 & 75 & $\begin{array}{c}0.99(0.75- \\
1.31)\end{array}$ & $\begin{array}{c}1.10(0.78- \\
1.56)\end{array}$ \\
\hline$\geq 4.15$ & 221 & 21 & 18 & $\begin{array}{c}1.29(0.78- \\
2.12)\end{array}$ & $\begin{array}{c}1.78(1.01- \\
3.13)\end{array}$ & 31 & 25 & $\begin{array}{c}1.54(1.01- \\
2.36)\end{array}$ & $\begin{array}{c}2.14(1.31- \\
3.50)\end{array}$ \\
\hline$P$ for difference & & & & 0.48 & 0.10 & & & 0.086 & 0.007 \\
\hline
\end{tabular}




\begin{tabular}{|c|c|c|c|c|c|c|c|c|c|}
\hline \multirow[b]{3}{*}{ Variable } & \multirow{3}{*}{$\begin{array}{l}\text { No. of } \\
\text { CHD } \\
\text { patients }\end{array}$} & \multicolumn{4}{|c|}{ 4-year follow-up } & \multicolumn{4}{|c|}{ Whole period of follow-up } \\
\hline & & \multicolumn{2}{|c|}{ No. of deaths } & \multicolumn{2}{|c|}{ Hazard ratios $(95 \% \mathrm{CI})^{\mathrm{a}}$} & \multicolumn{2}{|c|}{ No. of deaths } & \multicolumn{2}{|c|}{ Hazard ratios $(95 \% \mathrm{CI})^{\mathrm{a}}$} \\
\hline & & Total & CVD & $\begin{array}{l}\text { All-cause } \\
\text { mortality }\end{array}$ & $\begin{array}{c}\text { CVD } \\
\text { mortality }\end{array}$ & Total & CVD & $\begin{array}{l}\text { All-cause } \\
\text { mortality }\end{array}$ & $\begin{array}{c}\text { CVD } \\
\text { mortality }\end{array}$ \\
\hline \multicolumn{10}{|l|}{$\begin{array}{l}\text { Blood pressure, } \\
\mathrm{mm} \mathrm{Hg}\end{array}$} \\
\hline$<120 / 80$ & 443 & 38 & 28 & 1.00 & 1.00 & 50 & 34 & 1.00 & 1.00 \\
\hline$\geq 120-139 / 80-89$ & 717 & 61 & 42 & $\begin{array}{c}1.04(0.69- \\
1.57)\end{array}$ & $\begin{array}{c}1.01(0.62- \\
1.65)\end{array}$ & 81 & 54 & $\begin{array}{c}1.01(0.70- \\
1.45)\end{array}$ & $\begin{array}{c}1.06(0.68- \\
1.64)\end{array}$ \\
\hline$\geq 140 / 90$ & 751 & 81 & 59 & $\begin{array}{c}1.05(0.70- \\
1.57)\end{array}$ & $\begin{array}{c}1.06(0.66- \\
1.69)\end{array}$ & 101 & 71 & $\begin{array}{c}0.95(0.67- \\
1.36)\end{array}$ & $\begin{array}{c}1.03(0.67- \\
1.58)\end{array}$ \\
\hline$P$ for difference & & & & 0.97 & 0.97 & & & 0.92 & 0.97 \\
\hline \multicolumn{10}{|l|}{ Smoking status } \\
\hline Never & 1155 & 117 & 83 & 1.00 & 1.00 & 152 & 102 & 1.00 & 1.00 \\
\hline Past & 169 & 18 & 14 & $\begin{array}{c}0.84(0.50- \\
1.42)\end{array}$ & $\begin{array}{c}0.87(0.48- \\
1.58)\end{array}$ & 27 & 18 & $\begin{array}{c}1.01(0.65- \\
1.57)\end{array}$ & $\begin{array}{c}0.92(0.54- \\
1.57)\end{array}$ \\
\hline Current & 587 & 45 & 32 & $\begin{array}{c}0.80(0.54- \\
1.18)\end{array}$ & $\begin{array}{c}0.73(0.46- \\
1.17)\end{array}$ & 53 & 39 & $\begin{array}{c}0.76(0.53- \\
1.09)\end{array}$ & $\begin{array}{c}0.74(0.49- \\
1.13)\end{array}$ \\
\hline$P$ for difference & & & & 0.49 & 0.42 & & & 0.28 & 0.37 \\
\hline
\end{tabular}

Abbreviations: adjusted for alcohol consumption, marriage, family history of coronary heart disease, type of coronary heart disease, leisure-time physical activity, and body mass index.

CHD, coronary heart disease; CI, confidence interval; CVD, cardiovascular disease; HDL, high-density lipoprotein; LDL, low-density lipoprotein.

anti-apoptotic, ameliorate endothelial dysfunction) and gain dysfunction, which might contribute to inflammatory processes that promote atherosclerosis in CHD patients [13]. It suggests that controlling HDL-C at a reasonable range is necessary. Since LDL-C and HDL-C would be always detected as a pair of lipoprotein fractions in routine clinical examinations, we selected LDL-C, which was positively associated with the risk of mortality among CHD patients, instead of total cholesterol in the present study. High BP and cigarette use have been thought to be strong predictors for mortality among the general population. However, in the present study, we did not find any association of BP and cigarette use with the risk of mortality among patients with CHD. The lack of significant association between BP and risk of mortality might be due to high prevalence of using anti-hypertensive medication (48.9\%) among patients with CHD. As recommended by the guidelines [14], the tobacco user would be asked to quit smoking and pay more attention to secondary prevention, which partially explained the non-significant results. Taking multiple risk factors into account simultaneously might optimize the ability to estimate the prognosis of CHD patients. To the best of our knowledge, this is the first study that developed risk score assessments in Chinese patients with CHD.
Several previous studies have developed risk prediction scores for CVD risk among CHD patients with an acute setting [9]. TIMI risk score [15] provides a convenient bedside risk score for predicting 30-day mortality in patients with ST-elevation myocardial infarction while PURSUIT risk score [16] predicts 30-day outcomes for patients with ACS but without persistent ST-segment elevation. Granger et al. used 11,389 ACS patients enrolled in the Global Registry of Acute Coronary Events (GRACE) to develop the GRACE risk score for predicting mortality, but the median time of death was 4 days after hospital presentation [17]. Although these scoring assessments have been demonstrated significant discriminatory ability for mortality [9], they could not avoid the potential bias caused by premature death or the presence of occult diseases at baseline with the very short-term follow-up, and could not extend to all CHD outpatients.

Marschner et al. [8] developed a long-term risk stratification with 8557 CHD patients in the Long-Term Intervention With Pravastatin in Ischemic Disease (LIPID) study in Australia and New Zealand with an acute cardiac event 3-36 months before inclusion, which had been proposed as one of the first risk assessment scores for both ACS and stable CHD patients. As a strong predictor for 
Table 3: Risk score coefficients for all-cause mortality and cardiovascular mortality over 4 years and whole follow-up

\begin{tabular}{|c|c|c|c|c|}
\hline \multirow[t]{2}{*}{ Year of follow-up } & \multicolumn{2}{|c|}{ 4-year of follow-up } & \multicolumn{2}{|c|}{ Whole period of follow-up } \\
\hline & All-cause mortality & CVD mortality & All-cause mortality & CVD mortality \\
\hline \multicolumn{5}{|l|}{ Gender } \\
\hline Female & 0 & 0 & 0 & 0 \\
\hline Male & 7 & 8 & 5 & 7 \\
\hline \multicolumn{5}{|l|}{ Age, years } \\
\hline$<60$ & 0 & 0 & 0 & 0 \\
\hline $60-69$ & 13 & 16 & 12 & 15 \\
\hline$\geq 70$ & 21 & 21 & 20 & 20 \\
\hline \multicolumn{5}{|c|}{ Fasting blood glucose, $\mathrm{mmol} / \mathrm{L}$} \\
\hline$<5.6$ & 0 & 0 & 0 & 0 \\
\hline $5.6-6.9$ & 4 & 6 & 5 & 6 \\
\hline$\geq 7.0$ or known diabetes & 6 & 8 & 6 & 10 \\
\hline \multicolumn{5}{|l|}{ HDL cholesterol, $\mathrm{mmol} / \mathrm{L}$} \\
\hline$<1.03$ & 5 & 7 & 4 & 7 \\
\hline $1.03-1.54$ & 0 & 0 & 0 & 0 \\
\hline$\geq 1.55$ & 7 & 11 & 5 & 9 \\
\hline \multicolumn{5}{|l|}{ LDL cholesterol, mmol/L } \\
\hline$<2.59$ & 0 & 0 & 0 & 0 \\
\hline $2.59-4.14$ & 0 & 0 & 0 & 1 \\
\hline$\geq 4.15$ & 3 & 6 & 4 & 8 \\
\hline
\end{tabular}

Abbreviations: CVD, cardiovascular disease; HDL, high-density lipoprotein; LDL, low-density lipoprotein.

prognosis of CHD in our study, LDL-C was not included in LIPID score because of missing data [8]. HDL-C and diabetes status were only divided into two classes in the LIPID risk score. Battes et al. [18] recently developed a cardiovascular risk assessment model in patients with established coronary artery disease, consisting of 12,218 patients in EUROPA database, which also used diabetes status instead of glucose concentrations. In contrast to their results, we found that non-diabetic glucose concentrations (impaired fasting glucose, FBG: 5.6-6.9 $\mathrm{mmol} / \mathrm{L})$ and higher HDL-C levels $(\geq 1.55 \mathrm{mmol} / \mathrm{L})$ were associated with an increased risk of mortality, indicating that including FBG and HDL-C as dichotomization variables might be simple to calculate, but it would result in inaccuracy for risk stratification by missing important information.

Another kind of risk scores has been developed in the CHD population for predicting long-term cardiovascular outcomes to stratify CHD patients before therapy like percutaneous coronary intervention (PCI) and coronary artery bypass grafting (CABG) surgery [19-21]. Thus, some complicated variables like severity of illness (number of diseased vessels, ejection fraction, and hemodynamic state, et al.) and the presence of several comorbidities and prior history (cerebrovascular disease, peripheral arterial disease, congestive heart failure, malignant ventricular arrhythmia, chronic obstructive pulmonary disease, diabetes mellitus, and renal failure et al.) would be included in the risk stratification. Complicated procedures might result in seldom use in the clinic. Unlike these previous risk scores for CHD patients, our risk scores only integrated available traditional measurements which could be detected for every patient routinely and easy to use. Of course, incorporating more clinical results or novel biomarkers would increase the predictive discrimination [22]. But it does not meet our original objective for building a simple and economical assessment; and additional costs for the measurements 
Table 4: Hazard ratios for all-cause and cardiovascular mortality according to risk score quartiles among patients with coronary heart disease of the derivation cohort over 4 years and the whole follow-up

\begin{tabular}{|c|c|c|c|c|c|c|}
\hline \multirow[b]{2}{*}{ Model } & \multicolumn{4}{|c|}{ Quartiles of risk score } & \multirow{2}{*}{$P$ for trend } & \multirow{2}{*}{$\begin{array}{l}\text { Each } 1 \text { score } \\
\text { increase }\end{array}$} \\
\hline & Quartile 1 & Quartile 2 & Quartile 3 & Quartile 4 & & \\
\hline \multicolumn{7}{|l|}{ 4-year of follow-up } \\
\hline \multicolumn{7}{|l|}{ All-cause mortality } \\
\hline Range of scores & $0-13$ & $14-21$ & $22-29$ & $30-42$ & & \\
\hline No. of CHD patients & 510 & 443 & 482 & 476 & & \\
\hline No. of deaths & 11 & 14 & 57 & 98 & & \\
\hline $\begin{array}{l}\text { Multiple adjusted hazard } \\
\text { ratios }^{\text {a }}\end{array}$ & 1.00 & $\begin{array}{l}1.51(0.69- \\
3.34)\end{array}$ & $\begin{array}{c}6.18(3.23- \\
11.8)\end{array}$ & $\begin{array}{l}10.6(5.66- \\
20.0)\end{array}$ & $<0.001$ & $\begin{array}{l}1.10(1.08- \\
1.13)\end{array}$ \\
\hline \multicolumn{7}{|l|}{ Cardiovascular mortality } \\
\hline Range of scores & $0-16$ & $17-27$ & $28-35$ & $36-50$ & & \\
\hline No. of CHD patients & 503 & 471 & 475 & 462 & & \\
\hline No. of deaths & 6 & 9 & 42 & 72 & & \\
\hline $\begin{array}{l}\text { Multiple adjusted hazard } \\
\text { ratios }^{\mathrm{a}}\end{array}$ & 1.00 & $\begin{array}{c}1.63(0.58- \\
4.58)\end{array}$ & $\begin{array}{c}7.94(3.36- \\
18.8)\end{array}$ & $\begin{array}{l}15.1(6.53- \\
35.0)\end{array}$ & $<0.001$ & $\begin{array}{l}1.11(1.08- \\
1.13)\end{array}$ \\
\hline \multicolumn{7}{|l|}{ Whole period of follow-up } \\
\hline \multicolumn{7}{|l|}{ All-cause mortality } \\
\hline Range of scores & $0-11$ & $12-20$ & $21-26$ & $27-39$ & & \\
\hline No. of CHD patients & 465 & 484 & 469 & 493 & & \\
\hline No. of deaths & 15 & 24 & 71 & 122 & & \\
\hline $\begin{array}{l}\text { Multiple adjusted hazard } \\
\text { ratios }^{\mathrm{a}}\end{array}$ & 1.00 & $\begin{array}{l}1.64(0.86- \\
3.14)\end{array}$ & $\begin{array}{l}5.44(3.11- \\
9.53)\end{array}$ & $\begin{array}{c}8.86(5.15- \\
15.3)\end{array}$ & $<0.001$ & $\begin{array}{c}1.11(1.09- \\
1.13)\end{array}$ \\
\hline \multicolumn{7}{|l|}{ Cardiovascular mortality } \\
\hline Range of scores & $0-17$ & $18-26$ & $27-34$ & $35-52$ & & \\
\hline No. of CHD patients & 448 & 484 & 509 & 470 & & \\
\hline No. of deaths & 7 & 12 & 51 & 89 & & \\
\hline $\begin{array}{l}\text { Multiple adjusted hazard } \\
\text { ratios }^{\mathrm{a}}\end{array}$ & 1.00 & $\begin{array}{c}1.71(0.67- \\
4.35)\end{array}$ & $\begin{array}{c}7.25(3.28- \\
16.0)\end{array}$ & $\begin{array}{l}14.5(6.68- \\
31.6)\end{array}$ & $<0.001$ & $\begin{array}{l}1.10(1.08- \\
1.12)\end{array}$ \\
\hline
\end{tabular}

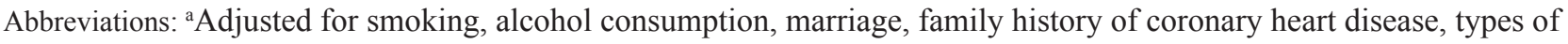
coronary heart disease, leisure-time physical activity, blood pressure categories, and body mass index.

CHD, coronary heart disease.

of unconventional biomarkers might limit the use of risk scores in clinical practice, especially in the developing countries. More importantly, our present risk scores, validated in the external cohort (AUROCs from 0.7360.756 , all $P<0.001$ ), could also offer strong discriminatory capacity when assessing with AUROC.

There are several limitations in the present study. First, we enrolled participants from hospitals where inpatients may have a more severe disease status, bias may occur. But we recruited both acute and chronic CHD patients, and some of them were electively admitted patients with mild status in order to reduce the bias. Second, although our analyses adjusted for an extensive set of CVD confounding factors, residual confounding due to the measurement error in the assessment of confounding factors or unmeasured factors for all CHD patients cannot be excluded. Third, we only measured the risk factors at baseline and did not further measure them during follow- 
Table 5: Discrimination measured by AUROC for risk score over 4 years and whole period of follow-up

\begin{tabular}{lcc}
\hline Model & AUROC & $P$ value \\
\hline Derivation cohort & & \\
4-year of follow-up & $0.754(0.72-0.79)$ & $<0.001$ \\
$\quad$ Risk score for all-cause mortality & $0.763(0.72-0.80)$ & $<0.001$ \\
$\quad$ Risk score for cardiovascular mortality & & $<0.001$ \\
Whole period of follow-up & $0.744(0.71-0.78)$ & $<0.001$ \\
$\quad$ Risk score for all-cause mortality & $0.762(0.73-0.80)$ & $<0.001$ \\
$\quad$ Risk score for cardiovascular mortality & & $<0.001$ \\
Validation cohort & & $<.756(0.70-0.82)$ \\
4-year of follow-up & $0.736(0.67-0.80)$ & $<0.001$ \\
$\quad$ Risk score for all-cause mortality & & $0.736(0.68-0.79)$ \\
Risk score for cardiovascular mortality & $0.743(0.69-0.80)$ & $<$ \\
Rhole period of follow-up & & \\
\hline
\end{tabular}

Abbreviations: AUROC, area under receiver operating characteristic curve.

up. Thus, more studies are warranted to confirm our risk assessments.

In conclusion, we have developed predictive risk scores for all-cause and cardiovascular mortality for patients with CHD. These simple risk scores are based on routinely available clinical information and could be easily calculated. These simple risk scores might be useful, in addition to CHD treatments and the shared decisionmaking tools between physicians and patients for a more intensive secondary prevention treatment.

\section{MATERIALS AND METHODS}

\section{Study population}

GCADC study was conducted as a derivation cohort. Details of the GCADC study about aims, selection, criteria and ascertainment of CHD have been published previously $[23,24]$. Participants who were admitted to the Cardiology Department of three superior specialty hospitals in Guangdong (Guangzhou Military General Hospital, Sun Yat-Sen Memorial Hospital, and First Affiliated Hospital of Sun Yat-Sen University) and diagnosed as coronary artery disease [International Classification of Diseases (ICD)-10 codes I20-I25] according to World Health Organization 1999/2000 guidelines [25, 26] between October 2008 and December 2011were recruited [23]. Briefly, we included 1911 CHD patients of 40 to 85 years old after excluding participants with incomplete data at baseline $(n=69)$. Patients with ACS were defined as the occurrence of any of unstable angina pectoris, ST-segment elevation myocardial infarction, and non-ST-segment elevation myocardial infarction within 3 months. Using the same inclusion and exclusion criteria and diagnosis of CHD as the GCADC study, we additionally recruited 1615 CHD patients via electronic medical records. After excluding 109 patients with incomplete data, we finally enrolled 1506 participants as the external validation cohort. Written informed consent was obtained from each patient of GCADC study; we did not obtain informed consent from participants in the validation cohort because we used anonymized data compiled from electronic medical records. The study plan for the GCADC study and the whole analysis plan were conducted according to the principles expressed in the Declaration of Helsinki and approved by the Sun Yat-Sen University Ethics Committee.

\section{Measurements}

In the GCADC study, each patient's general information of examination date, birth date, gender, address, education level, marriage, leisure-time physical activity, smoking habits, alcohol consumption, dietary intake, family history of diseases, and use of medication before admission was ascertained by a standardized questionnaire and a validated food frequency questionnaire [27] through a face-to-face interview. We classified smoking habits and alcohol consumption into three groups: never, past, or current. Current smoking 
was defined as regularly at least one cigarette per day and lasting for more than 6 months before the study, and current alcohol drinking was defined as drinking any type of alcoholic beverages at least once a week and lasting for half a year before the study. Family history of CHD was self-reported, including CHD history for all first-degree relatives.

Clinical characteristics of patients from the derivation and validation cohorts were extracted from the electronic record system. At admission, height and weight were measured by trained nurses. Body mass index (BMI) was defined as the weight in kilograms divided by the square of height in meters. Two BP determinations were made after the patients had been sitting at least 5 minutes, and the average was used for the analyses. Blood was drawn at the baseline examination after an overnight fasting. Lipids and FBG were determined by standardized methods using the Hitachi automatic analyzer 7600-020 (Hitachi, Tokyo, Japan).

\section{Prospective follow-up}

Annual follow-up information was obtained from hospital medical records of readmission, telephone contacts with patients or their immediate family members, and death registration at the Guangdong Provincial Center for Disease Control and Prevention. The current surveys were followed to the end of June 2015 or patient's death if the date was prior to June 2015. We used the ICD codes to code the cause of death; the ICD codes I00-I99 were classified as CVD deaths.

\section{Statistical analyses}

Differences in baseline characteristics from the derivation cohort according to death status were tested by the general linear model for continuous variables and logistic regression for categorical variables after adjusting age and gender (except for age and gender). Major traditional risk factors (age, FBG, HDL-C, LDL-C, BP, and cigarette use) have been grouped into three classes: (1) age, $<60,60-69$, $\geq 70$ years; (2) FBG, <5.6, 5.6-6.9, $\geq 7.0 \mathrm{mmol} / \mathrm{L}$ and known diabetes (diabetes diagnosed before the baseline examinations); (3) HDL-C, $<1.03$, $1.03-1.54, \geq 1.55 \mathrm{mmol} / \mathrm{L}$; (4) LDL-C, <2.59, 2.59-4.14, $\geq 4.15 \mathrm{mmol} / \mathrm{L}$; (5) BP, <120/80, 120-139/80-89, $\geq 140 / 90$ mm Hg; (6) smoking status, never, past, current. Cox proportional hazards models were performed to determine the associations between baseline major risk factors (gender, age, FBG, HDL-C, LDL-C, BP, and cigarette use) and the risk of all-cause and CVD mortality in both 4-year and whole follow-up periods, respectively. All analyses were adjusted for alcohol drinking, marriage, leisure-time physical activity, family history of CHD, type of CHD, and BMI. The selected risk factors were included as categories in the risk score systems to allow for possible non-linear effects of the factors and so that a risk score can be evaluated for a given individual by simply summing scores corresponding with the categories for each factor. We gave a risk score for each category of each factor, except for BP and smoking status because BP and smoking were not significant predictors in all multivariable-adjusted Cox models. These scores were beta coefficients, formed with the Cox model, multiplied by 10 and rounded to the closest integer [4]. The risk score for an individual was obtained by summing the scores for the appropriate level of each of the risk factors. The associations of risk scores for all-cause and cardiovascular mortality over 4-year and whole period of follow-up were estimated by Cox models after adjusting for smoking, alcohol drinking, marriage, leisure-time physical activity, family history of CHD, types of CHD, BP categories, and BMI. Risk scores were included in the Cox model in two ways: as quartiles and as continuous variables. We additionally conducted the Pearson correlation coefficients to assess the correlation between BP and other traditional factors.

The discrimination of capacity of different risk score groups for the derivation cohort and the validation cohort was assessed by the AUROC. Statistical significance was considered to be $P<0.05$. All statistical analyses were performed using PASW for Windows, version 20.0 (IBM SPSS Inc., Chicago, IL).

\section{CONFLICTS OF INTEREST}

The authors declare no conflicts of interest.

\section{REFERENCES}

1. Mozaffarian D, Benjamin EJ, Go AS, Arnett DK, Blaha MJ, Cushman M, Das SR, de Ferranti S, Despres JP, Fullerton HJ, Howard VJ, Huffman MD, Isasi CR, et al. Heart Disease and Stroke Statistics-2016 Update: A Report From the American Heart Association. Circulation. 2016; 133:e38-60.

2. Ford ES, Ajani UA, Croft JB, Critchley JA, Labarthe DR, Kottke TE, Giles WH, Capewell S. Explaining the decrease in U.S. deaths from coronary disease, 1980-2000. N Engl J Med. 2007; 356:2388-2398.

3. Critchley J, Liu J, Zhao D, Wei W, Capewell S. Explaining the increase in coronary heart disease mortality in Beijing between 1984 and 1999. Circulation. 2004; 110:1236-1244.

4. Balkau B, Hu G, Qiao Q, Tuomilehto J, Borch-Johnsen K, Pyorala K. Prediction of the risk of cardiovascular mortality using a score that includes glucose as a risk factor. The DECODE Study. Diabetologia. 2004; 47:2118-2128.

5. Wilson PW, D'Agostino RB, Levy D, Belanger AM, Silbershatz H, Kannel WB. Prediction of coronary heart disease using risk factor categories. Circulation. 1998; 97:1837-1847. 
6. Chambless LE, Folsom AR, Sharrett AR, Sorlie P, Couper D, Szklo M, Nieto FJ. Coronary heart disease risk prediction in the Atherosclerosis Risk in Communities (ARIC) study. J Clin Epidemiol. 2003; 56:880-890.

7. Conroy RM, Pyorala K, Fitzgerald AP, Sans S, Menotti A, De Backer G, De Bacquer D, Ducimetiere P, Jousilahti P, Keil U, Njolstad I, Oganov RG, Thomsen T, et al. Estimation of ten-year risk of fatal cardiovascular disease in Europe: the SCORE project. Eur Heart J. 2003; 24:987-1003.

8. Marschner IC, Colquhoun D, Simes RJ, Glasziou P, Harris P, Singh BB, Friedlander D, White H, Thompson $\mathrm{P}$, Tonkin A. Long-term risk stratification for survivors of acute coronary syndromes. Results from the Long-term Intervention with Pravastatin in Ischemic Disease (LIPID) Study. LIPID Study Investigators. J Am Coll Cardiol. 2001; 38:56-63.

9. Morrow DA. Cardiovascular risk prediction in patients with stable and unstable coronary heart disease. Circulation. 2010; 121:2681-2691.

10. Goliasch G, Kleber ME, Richter B, Plischke M, Hoke M, Haschemi A, Marculescu R, Endler G, Grammer TB, Pilz S, Tomaschitz A, Silbernagel G, Maurer G, et al. Routinely available biomarkers improve prediction of long-term mortality in stable coronary artery disease: the Vienna and Ludwigshafen Coronary Artery Disease (VILCAD) risk score. Eur Heart J. 2012; 33:2282-2289.

11. Ding D, Li X, Qiu J, Li R, Zhang Y, Su D, Li Z, Wang M, Lv X, Wang D, Yang Y, Xia M, Li D, Hu G, Ling W. Serum lipids, apolipoproteins, and mortality among coronary artery disease patients. Biomed Res Int. 2014; 2014:709756.

12. Angeloni E, Paneni F, Landmesser U, Benedetto U, Melina G, Luscher TF, Volpe M, Sinatra R, Cosentino F. Lack of protective role of HDL-C in patients with coronary artery disease undergoing elective coronary artery bypass grafting. European heart journal. 2013; 34:3557-3562.

13. Rosenson RS, Brewer HB, Jr., Ansell BJ, Barter P, Chapman MJ, Heinecke JW, Kontush A, Tall AR, Webb NR. Dysfunctional HDL and atherosclerotic cardiovascular disease. Nat Rev Cardiol. 2016; 13:48-60.

14. Smith SC, Jr., Benjamin EJ, Bonow RO, Braun LT, Creager MA, Franklin BA, Gibbons RJ, Grundy SM, Hiratzka LF, Jones DW, Lloyd-Jones DM, Minissian M, Mosca L, et al. AHA/ACCF secondary prevention and risk reduction therapy for patients with coronary and other atherosclerotic vascular disease: 2011 update: a guideline from the American Heart Association and American College of Cardiology Foundation endorsed by the World Heart Federation and the Preventive Cardiovascular Nurses Association. J Am Coll Cardiol. 2011; 58:2432-2446.

15. Morrow DA, Antman EM, Charlesworth A, Cairns R, Murphy SA, de Lemos JA, Giugliano RP, McCabe CH, Braunwald E. TIMI risk score for ST-elevation myocardial infarction: A convenient, bedside, clinical score for risk assessment at presentation: An intravenous nPA for treatment of infarcting myocardium early II trial substudy. Circulation. 2000; 102:2031-2037.

16. Boersma E, Pieper KS, Steyerberg EW, Wilcox RG, Chang WC, Lee KL, Akkerhuis KM, Harrington RA, Deckers JW, Armstrong PW, Lincoff AM, Califf RM, Topol EJ, et al. Predictors of outcome in patients with acute coronary syndromes without persistent ST-segment elevation. Results from an international trial of 9461 patients. The PURSUIT Investigators. Circulation. 2000; 101:2557-2567.

17. Granger CB, Goldberg RJ, Dabbous O, Pieper KS, Eagle KA, Cannon CP, Van De Werf F, Avezum A, Goodman SG, Flather MD, Fox KA. Predictors of hospital mortality in the global registry of acute coronary events. Arch Intern Med. 2003; 163:2345-2353.

18. Battes L, Barendse R, Steyerberg EW, Simoons ML, Deckers JW, Nieboer D, Bertrand M, Ferrari R, Remme WJ, Fox K, Takkenberg JJ, Boersma E, Kardys I. Development and validation of a cardiovascular risk assessment model in patients with established coronary artery disease. Am J Cardiol. 2013; 112:27-33.

19. MacKenzie TA, Malenka DJ, Olmstead EM, Piper WD, Langner C, Ross CS, O'Connor GT. Prediction of survival after coronary revascularization: modeling short-term, mid-term, and long-term survival. Ann Thorac Surg. 2009; 87:463-472.

20. Weintraub WS, Grau-Sepulveda MV, Weiss JM, Delong ER, Peterson ED, O'Brien SM, Kolm P, Klein LW, Shaw RE, McKay C, Ritzenthaler LL, Popma JJ, Messenger JC, et al. Prediction of long-term mortality after percutaneous coronary intervention in older adults: results from the National Cardiovascular Data Registry. Circulation. 2012; 125:1501-1510.

21. Wu C, Camacho FT, King SB, 3rd, Walford G, Holmes DR, Jr., Stamato NJ, Berger PB, Sharma S, Curtis JP, Venditti FJ, Jacobs AK, Hannan EL. Risk stratification for long-term mortality after percutaneous coronary intervention. Circ Cardiovasc Interv. 2014; 7:80-87.

22. Beatty AL, Ku IA, Bibbins-Domingo K, Christenson RH, DeFilippi CR, Ganz P, Ix JH, Lloyd-Jones D, Omland T, Sabatine MS, Schiller NB, Shlipak MG, Skali H, et al. Traditional Risk Factors Versus Biomarkers for Prediction of Secondary Events in Patients With Stable Coronary Heart Disease: From the Heart and Soul Study. J Am Heart Assoc. 2015; 4.

23. Ding D, Qiu J, Li X, Li D, Xia M, Li Z, Su D, Wang Y, Zhang Y, Zhang J, Lv X, Xiao Y, Hu G, Ling W. Hyperglycemia and mortality among patients with coronary artery disease. Diabetes Care. 2014; 37:546-554.

24. Li X, Zhang Y, Wang M, Lv X, Su D, Li Z, Ding D, Xia M, Qiu J, Hu G, Ling W. The prevalence and awareness of cardiometabolic risk factors in Southern Chinese population with coronary artery disease. ScientificWorldJournal. 2013; 2013:416192.

25. Gibbons RJ, Chatterjee K, Daley J, Douglas JS, Fihn SD, Gardin JM, Grunwald MA, Levy D, Lytle BW, O'Rourke 
RA, Schafer WP, Williams SV. ACC/AHA/ACP-ASIM guidelines for the management of patients with chronic stable angina: executive summary and recommendations. A Report of the American College of Cardiology/American Heart Association Task Force on Practice Guidelines (Committee on Management of Patients with Chronic Stable Angina). Circulation. 1999; 99:2829-2848.

26. Braunwald E, Antman EM, Beasley JW, Califf RM, Cheitlin MD, Hochman JS, Jones RH, Kereiakes D, Kupersmith J, Levin TN, Pepine CJ, Schaeffer JW, Smith EE, 3rd, et al. ACC/AHA guidelines for the management of patients with unstable angina and non-ST-segment elevation myocardial infarction: executive summary and recommendations. A report of the American College of Cardiology/American Heart Association task force on practice guidelines (committee on the management of patients with unstable angina). Circulation. 2000; 102:1193-1209.

27. Zhang B, Wang P, Chen CG, He QQ, Zhuo SY, Chen YM, $\mathrm{Su}$ YX. Validation of an FFQ to estimate the intake of fatty acids using erythrocyte membrane fatty acids and multiple 3d dietary records. Public Health Nutr. 2010; 13:1546-1552. 